\title{
Prevalence and Risk Factors of Perinatal Asphyxia in a Tertiary Care Level Hospital, Harari Regional State, Ethiopia
}

\section{Arif Hussen Jamie ${ }^{1}$ and Mohammed Z. Abdosh ${ }^{2}$}

${ }^{1}$ Department of Paediatrics Nursing, Harar Health Science College, East Ethiopia

${ }^{2}$ Department of Public Health, Harar Health Science College, East Ethiopia

\section{Correspondence: \\ Arif Hussen \\ Department of Paediatric Nursing \\ Harar Health Science College, \\ East Ethiopia \\ Email: arifhussen.ah@gmail.com}

DOI:10.3126/jnps.v39i2.26408

Submitted on: $2020-01-02$

Accepted on: 2020-03-18

Acknowledgements: None

Funding: Nil

Conflict of Interest: None declared

Permission form IRB: Yes

To cite this article: Jamie A $\mathrm{H}$. Abdosh MZ. Prevalence and risk factors of perinatal asphyxia in a tertiary care level hospital, Harari regional state, Ethiopia. J Nepal Paediatr Soc. 2019;39(1):103-8.

\begin{abstract}
Introduction: Globally birth asphyxia continues to present a major clinical problem. It is one of the common and leading causes of perinatal and neonatal mortality and morbidity especially in developing countries.

Methods: A cross-sectional study was conducted among newborns in a tertiary level hospital, Ethiopia from February to July 2019. Systematic random sampling technique was used to select the study subjects. Multivariate logistic regression analysis was used to identify factors associated with the perinatal asphyxia among newborns.
\end{abstract}

Results: Of the newborns, $32 \%$ had perinatal asphyxia and factors significantly associated were anaemia during pregnancy (adjusted $\mathrm{OR}=2.99,95 \%$ CI: $1.07-8.35$ ), chronic hypertension (adjusted $\mathrm{OR}=4.89,95 \% \mathrm{CI}: 1.16-20.72)$ and low birth weight newborns (adjusted OR $=3.31,95 \% \mathrm{CI}: 1.308-8.37$ ).

Conclusions: Maternal anaemia during pregnancy, chronic hypertension and low birth weight were significantly associated with perinatal asphyxia. Therefore, early screening and appropriate intervention during pregnancy and intra-partum might reduce perinatal asphyxia among newborns.

Key words: Harari; newborn; prevalence; perinatal asphyxia

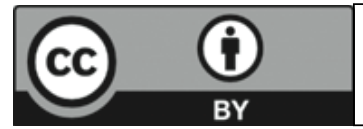

This work is licensed under creative common attribution 3.0 license 


\section{INTRODUCTION}

The neonatal period is the first 28 days of life but also the most vulnerable time for survival. Globally, 45\% under-five children death occurs during the neonatal period. Perinatal asphyxia is defined as an oxygen deprivation that occurs around the time of birth and may be caused by several perinatal events. It is known that beside using a single indicator like that of APGAR (Appearance, Pulse, Grimace, Activity and Respiration) score simply delayed respiration is also an indicator for neonatal asphyxia which leads to brain damage. ${ }^{1,2}$ Globally birth asphyxia continues to present a major clinical problem. ${ }^{3}$ And it is one of the common and leading causes of perinatal and neonatal mortality and morbidity especially in developing countries. ${ }^{4}$

Four million babies are born with asphyxia each year. According to statistics by WHO, in developing countries $3 \%$ of infants (3.6 million babies) suffer from moderate to severe asphyxia, of whom $23 \%(840,000)$ die which equates to nearly one million neonatal deaths per year. ${ }^{5}$ In countries with high neonatal mortality rates, the death rate is eight times that of countries with low NMRs and almost the same number suffer from the associated consequences. ${ }^{6}$

Africa accounts for $11 \%$ of the world's population but more than $25 \%$ of the world's new-born deaths. Of every 4 children who die in Africa, one is a newborn. ${ }^{7}$ Birth asphyxia is the fifth largest cause of under-five mortality. ${ }^{8}$ Ethiopia, one of the countries with the highest neonatal mortality in the world, is responsible for 29 deaths per 1,000 live births. ${ }^{9}$ Obstetric causes notably preterm birth, severe infection, and birth asphyxia continue to account for a large proportion of the deaths. ${ }^{10}$

The effect of birth asphyxia is not limited only to death but also has a short and long term neurodevelopment sequelae, including cognitive and motor disabilities which are almost untreatable. ${ }^{11}$ Different studies showed that the survivors of asphyxia developed hypoxic-ischemic encephalopathy, ${ }^{12}$ post-traumatic stress disorders, ${ }^{13}$ low cognitive functions ${ }^{14}$ and neurological sequel. ${ }^{15}$ A certain experimental study also revealed that nearly $25 \%$ of the newborns who survived birth asphyxia developed neurological disorders, such as cerebral palsy and certain neurodevelopment and learning disabilities. ${ }^{16}$

A series of various maternal, obstetrical and foetal factors cause hypoxia in the foetus and asphyxia in the new-born, which is decreased blood flow and oxygenation. ${ }^{17}$ Birth asphyxia can be caused by events that have their roots in $50 \%$ of cases primarily ante-partum, $40 \%$ cases intra-partum and remaining $10 \%$ of cases in postpartum period. ${ }^{18}$

There are insufficient studies conducted on perinatal asphyxia in our country. Therefore, this study was aimed to assess the prevalence and associated factors of perinatal asphyxia among newborns in tertiary level hospital, Harari regional state, Ethiopia.

\section{METHODS}

The study is a institutional based cross sectional study conducted at a tertiary level hospital in Hahrari, Ethiopia from February to July, 2019. Single population proportion formula was used to calculate the sample size and the following assumptions were made: The formula to calculate the sample size was $n=(Z \alpha / 2)^{2} p(1-p) / d^{2}$, where $\mathrm{n}=$ number of the study subjects, $\mathrm{Z}=$ the standardised normal distribution curve value for the $95 \%$ confidence interval (1.96), $\mathrm{P}=$ the prevalence of birth asphyxia was $30.8 \%=0.308$ and $d=$ the desired precision of the estimate (the margin of error between the sample and population, $5 \%)=$ $0.05=(1.96)^{2} \times 0.308(1-0.308) /(0.05)^{2}=328$. After correction method was applied the final sample size was 258 and systematic random sampling was applied. All live newborns during the data collection period and selected as sample were included in the study, but newborns with congenital anomalies and babies born by cesarean section were excluded. APGAR score was one of the criteria used to define birth asphyxia in this study, due to unavailability of blood gas analysis in the hospital. The APGAR score provides convenient shorthand method for reporting the status of the newborn infant and to initiate resuscitation, especially in resource-limited settings like ours. 
After data collection, the questionnaire was checked for completeness and coded. Then data were entered in to Epi-info version 3.5.3. Then after, the data were exported to SPSS version-20. Mono-variate, Bi-variate and multi-variate analysis were done. The variable with p-value $<0.05$ in multiple logistic regressions was considered as it has statistically significant association. Ethical clearance was obtained from the institutional review committee. Consent was obtained from administrative body of the hospital and the participants. Confidentiality of the data has been kept throughout the study.

\section{RESULTS}

The demographic characteristics are presented in Table 1. During the study period, 668 live newborns were delivered, among whom 258 live births were selected for the study; 256 participants participated in the study making the response rate of $99.2 \%$. Majority of the participants' age was falling in the age category of 25 to 29 years. One hundred twelve $(43.75 \%)$ of them were housewives and only $15(5.86 \%)$ had college/university education. Most mothers 166 (64.84\%) were multipara and greater than half $178(69.53 \%)$ did not have bad obstetric history. (Table 1).

In our study, there were 109 (42.58\%) male and $147(57.42 \%)$ female neonates. Among the newborns, $23(8.98 \%)$ were delivered with very low birth weight $(<1.5 \mathrm{~kg}), 97(37.89 \%)$ were delivered with low birth weight $(<2.5 \mathrm{~kg})$ and the rest $136(53.13 \%)$ were delivered with normal birth weight $(2.5-4 \mathrm{~kg})$. In terms of gestational age, almost all 244 (95.31\%) of them were born at term, only five (1.95\%) and seven $(2.73 \%)$ were born pre term and post term respectively. Only 81 (31.64\%) of the neonates were assessed as perinatal asphyxia immediately after delivery. (Figure 1).

In bi-variate logistic regression analysis, anaemia during pregnancy, chronic hypertension, meconium stained amniotic fluid, and low birth weight were significantly associated with neonatal asphyxia. Variables which showed statistically significant associations with neonatal asphyxia in the bivariate analysis were entered in to a multivariate logistic regression model to see the independent
Table 1. Maternal socio-demographic and obstetric characteristics

\begin{tabular}{|c|c|c|c|}
\hline Variables & Categories & Frequency & Percent \\
\hline \multirow[t]{5}{*}{ Mother's age } & $\leq 19$ years & 20 & 7.81 \\
\hline & $20-24$ years & 66 & 25.78 \\
\hline & $25-29$ years & 94 & 36.72 \\
\hline & $30-34$ years & 55 & 21.48 \\
\hline & $\geq 35$ years & 21 & 8.20 \\
\hline \multirow{3}{*}{$\begin{array}{l}\text { Maternal } \\
\text { occupation }\end{array}$} & Housewife & 112 & 43.75 \\
\hline & $\begin{array}{l}\text { Private } \\
\text { employee }\end{array}$ & 95 & 37.11 \\
\hline & $\begin{array}{l}\text { Government } \\
\text { employee }\end{array}$ & 49 & 19.14 \\
\hline \multirow[t]{4}{*}{$\begin{array}{l}\text { Maternal } \\
\text { educational } \\
\text { status }\end{array}$} & $\begin{array}{l}\text { Unable to } \\
\text { read and } \\
\text { write }\end{array}$ & 51 & 19.92 \\
\hline & Primary & 107 & 41.80 \\
\hline & Secondary & 83 & 32.42 \\
\hline & $\begin{array}{l}\text { College/ } \\
\text { university }\end{array}$ & 15 & 5.86 \\
\hline \multirow[t]{2}{*}{ Parity } & Primi & 90 & 35.16 \\
\hline & Multi-para & 166 & 64.84 \\
\hline \multirow{2}{*}{$\begin{array}{l}\text { Duration of } \\
\text { current } \\
\text { pregnancy }\end{array}$} & $\leq 37$ weeks & 66 & 25.78 \\
\hline & $>37$ weeks & 190 & 74.22 \\
\hline \multirow{2}{*}{$\begin{array}{l}\text { History of } \\
\text { adverse } \\
\text { pregnancy } \\
\text { outcome }\end{array}$} & Yes & 78 & 30.47 \\
\hline & No & 178 & 69.53 \\
\hline \multirow{6}{*}{$\begin{array}{l}\text { Complication/ } \\
\text { illnesses } \\
\text { during } \\
\text { pregnancy }\end{array}$} & Anemia & 61 & 23.83 \\
\hline & $\begin{array}{l}\text { Preeclampsia/ } \\
\text { eclampsia }\end{array}$ & 11 & 4.30 \\
\hline & $\begin{array}{l}\text { Chronic } \\
\text { hypertension }\end{array}$ & 43 & 16.80 \\
\hline & APH & 3 & 1.17 \\
\hline & PROM & 9 & 3.52 \\
\hline & No illness & 129 & 50.39 \\
\hline
\end{tabular}

effect of each potential determinant while controlling for possible confounders. After 


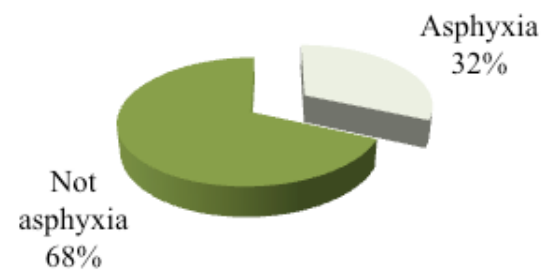

Figure 1. Breathing status of neonates immediately after delivery

controlling the effect of other predictor variables, the multivariate logistic regression analysis showed statistically significant association between anaemia during pregnancy, chronic hypertension, low birth weight and neonatal asphyxia with pvalue $<0.05$. Neonates delivered from anaemic mothers were three times more likely to develop asphyxia as compared to neonates from nonanaemic mothers during pregnancy $(\mathrm{AOR}=2.992$, 95\% CI: $1.073-8.35$ ).

Neonates from mothers who had chronic hypertension were five times more likely to develop asphyxia compared to those newborns from mothers who did not have hypertension (AOR $=4.9,95 \%$ CI: 1.16-20.7). Low birth weight newborns were three times more likely to develop perinatal asphyxia compared to normal weight newborns (adjusted OR $=3.309,95 \%$ CI: 1.308 , 8.368).

\section{DISCUSSION}

The prevalence of perinatal asphyxia among newborns was $32.8 \%$. This finding is higher than those of other studies conducted in Dire Dawa (Ethiopia) (2.5\%), ${ }^{19}$ Nepal $(2.69 \%),{ }^{20}$ Tanzania $(21.1 \%),{ }^{21}$ Malawi $(6.1 \%)^{22}$ and Iran $(1 \%)^{23}$ respectively. The finding in differences might have been contributed due to the differences in the study population, different geographical regions as well as different context in different countries.

In this study, anaemia during pregnancy was found to be significantly associated with perinatal asphyxia. This is similar with study findings in rural districts of Pakistan. ${ }^{24}$ It is obvious that anaemia during pregnancy will affect foetal development and complicate the birth and also anaemia causes intrapartum hypoxia. Thus, anaemia must be looked for during antenatal follow up and treat it if found during pregnancy.

In this study, maternal history of chronic hypertension was found to be significantly associated with perinatal asphyxia. This finding is in line with study done in India which reported that chronic hypertension was found to be a risk factor for perinatal asphyxia. ${ }^{25}$ Maternal hypertension leads to a decrement in placental blood flow. Thus, maternal hypertension directly affects the foetal wellbeing in the uterus and it also directly contributes to neonatal asphyxia at birth. Maternal hypertension is also a well known etiology of preterm deliveries and hence, this may also contribute to perinatal asphyxia. It is known that women with pregnancy induced hypertension have higher chances of preterm babies in comparison to normotensive women. Preterm babies have much higher risk of birth asphyxia and more complications of immaturity and requiring intensive neonatal care, which might implicate draining financial and other resources. Low birth weight was found to be a significant factor for perinatal asphyxia in this study. This finding is in corroboration with previous study findings in Indonesia, Thailand and Bangladesh. ${ }^{26-28}$ The primary cause of low birth weight is premature birth (being born before 37 weeks gestation). A baby being born before 37 completed weeks of pregnancy may develop birth asphyxia due to an insufficient amount of surfactant in the lungs. Surfactant creates a continuously reforming surface layer over the alveoli which reduces surface tension, prevents atelectasis and maintains alveolar stability. A deficiency in pulmonary surfactant production causes respiratory distress syndrome. ${ }^{29}$ The findings in our study is in contrast to the result of the study conducted in Nigeria. ${ }^{30}$ This discrepancy in results might have been due to the difference in the socio-economic status of the study population as well as the different geographical and environmental factors.

This study is a single centric study which might not represent the entire population. Another limitation of this study was selection bias because only neonates delivered at the hospital were included. It is known that many mothers give birth at home, so 
it may not represent the whole regional births. Despite certain limitations, the result of this study will help the stakeholders to identify the prevalence and associated factors of perinatal asphyxia among newborns.

\section{CONCLUSIONS}

The findings of this study gave insight on the prevalence of perinatal asphyxia among newborns in Harari regional state. The study showed that there is significant association between anaemia during pregnancy, chronic hypertension and low birth weight and perinatal asphyxia among newborns in Harari regional state.

\section{REFERENCES}

1. World Health Organisation and Others, Guidelines on Basic Newborn Resuscitation. World Heal Organ, 2012. ISBN: 978924150369 3. https://apps.who.int/iris/handle/10665/75157.

2. Fattuoni C, Palmas F, Noto A, Fanos V, Barberini L. Perinatal asphyxia: A review from a metabolomics perspective. Molecules. 2015;20(4):7000-16. DOI: http://curoservice.com/Accessedon12/2/2015

3. World health organisation, Global Health Organisation (GHO) Data. Available from: http://www.who.int/whoghod/ whoghodt/. Accessed November 20, 2016.

4. Lopez AD, Mathers CD. Measuring the Global Burden of Disease and Epidemiological Transitions: 2002-2030. Ann Trop Med Parasitol. 2006;100:481-99. DOI:https://doi.org/10.1179/136485906x97417

5. Federal democratic republic of Ethiopia Ministry of Health, BEmONC-LRP (2013) Best practice in maternal and newborn care Maternal Death Surveillance and Response.

6. Masoud O, Shima T, Shabnam M, Mostafa P, Majid GM. Serum Hsp70 Antigen: Early Diagnosis Marker in Perinatal Asphyxia. Iranian Journal of Pediatrics. 2010;25(2). DOI:https://doi.org/10.5812/ijp.381,

7. Lawn J, Katarzyna WK, Cousens S. Estimating the causes of 4 million neonatal deaths in the year 2000 . Int $\mathbf{J}$ Epidemiol. 2006;35(3):706-18. DOI: https://doi.org/10.1093/ije/dyl043

8. Ilah BG, Aminu MS, Musa A, Adelakun MB, Adeniji AO. Prevalence and Risk Factors for Perinatal Asphyxia as Seen at a Specialist Hospital in Gusau, Nigeria Sub-Saharan. Afr J Med. 2015;2(2):64. DOI: 10.4103/2384-5147.157421

9. Ethiopia Demographic and Health Survey. In: Key Indicators Report. Addis Ababa, Ethiopia: Central Statistical Agency; October 2016.

10. Antonucci R, Porcella A, Pilloni MD. Perinatal asphyxia in the term newborn. JPNIM. 2014;3(2):e030269. DOI: 10.7363/030269

11. Kiyani AN, Khushdil A, Ehsan A. Perinatal factors leading to birth asphyxia among term newborns in a tertiary care hospital. Iran J Pediatr. 2014;24(5):637. PMID: 25793074

12. Ahearne CE, Boylan GB, Murray DM. Short and long term prognosis in perinatal asphyxia: An update. World J clin pediatr. 2016;5(1):67. DOI: 10.5409/wjcp.v5.i1.67

13. Horsch A, Jacobs I, Gilbert L, Favrod C, Schneider J, Harari MM, et al. Impact of perinatal asphyxia on parental mental health and bonding with the infant: a questionnaire survey of Swiss parents. BMJ Paediatr Open. 2017;1(1):e000059.

14. Ehrenstein V, Pedersen L, Grijota M, Nielsen GL, Rothman KJ, Sørensen HT. Association of Apgar score at five minutes with long-term neurologic disability and cognitive function in a prevalence study of Danish conscripts. BMC Pregnancy and childb. 2009;9(1):14. DOI: 10.1186/1471-2393-9-14

15. Shireen N, Nahar N, Mollah A. Risk factors and short-term outcome of birth asphyxiated babies in Dhaka Medical College Hospital. Bangla J of Child Health. 2009,33(3):83-89. https://doi.org/10.3329/bjch.v33i3.5688

16. Herrera MI, Otero-Losada M, Udovin LD, Kusnier C, Kölliker-Frers R, de Souza W, et al. Could Perinatal Asphyxia Induce a Synaptopathy? New Highlights from an Experimental Model. Neural plasticity. 2017. DOI: https:// dx.doi.org/10.1155\%2F2017\%2F3436943 
17. Berglund S, Grunewald C, Pettersson H, Cnattingius S. Risk factors for asphyxia associated with substandard care during labor. Acta Obstet Gynecol Scand. 2010;89:39-48. DOI: 10.3109/00016340903418751

18. American Heart Association Guidelines for cardiopulmonary resuscitation (CPR) and emergency cardiovascular care (ECC) of paediatric and neonatal Patients: Pediatric basic life support. Pediatr. 117:e989-e1004. DOI: 10.1542/ peds.2006-0219

19. Ibrahim NA, Muhye A, Abdulie S. Prevalence of Birth Asphyxia and Associated Factors among Neonates Delivered in Dilchora Referral Hospital, in Dire Dawa, Eastern Ethiopia. Clin Mother Child Health. 2017;14(4). DOI: $10.4172 / 2090-7214.1000279$

20. Dongol S, Singh J, Shrestha S, Shakya A. Clinical Profile of Birth Asphyxia in Dhulikhel Hospital: A Retrospective Study. J Nepal Paediatr Soc. 2010;30(3).141-6. DOI: https://doi.org/10.3126/jnps.v30i3.3916

21. Sepeku A, Kohi TW. Treatment outcomes of neonatal asphyxia at a national hospital in dar es salaam, Tanzania. Afr J Nurs Midwifery. 2011;13:43-56. DOI: http://hdl.handle.net/10520/EJC19378

22. Chikuse B, Chirwa E, Maluwa A, Malata A, Odland J. Midwives' adherence to guidelines on the management of birth asphyxia in Malawi. Open J Nurs. 2012;2:351-7. DOI: 10.4236/ojn.2012.24052

23. Boskabadi H, Ashrafzadeh F, Doosti H, Zakerihamidi M. Assessment of Risk Factors and Prognosis in Asphyxiated Infants. Iran J Pediatr. 2015;25:e2006. DOI: https://dx.doi.org/10.5812\%2Fijp.2006

24. Farhana T, Rizvi A, Ariff S, Soofi S, Bhutta ZA. Risk factors associated with birth asphyxia in rural district matiari, Pakistan: a case control study. Int J Clin Med. 2014;5:1430-41. DOI: 10.4236/ijcm.2014.521181

25. Bahubali Gane, Vishnu Bhat B, Ramachandra Rao, Nandakumar S, Adhisivam B, Rojo Joy, et.al. Antenatal and intrapartum risk factors for perinatal asphyxia: A case control study. Curr Pediatr Res. 2013;17(2):119-122.

26. Martono T. Risk factors for birth asphyxia: Folia Medica Indonesiana. 2011;47(4):211-4.

27. Pitsawong C. Risk Factors Associated with Birth Asphyxia in Phramongkutklao Hospital. Thai J Obstet Gynaecol, 2011;19(4):165-71.

28. Solayman M, Hoque S, Akber T, Islam MI, Islam MA. Prevalence of Perinatal Asphyxia with Evaluation of Associated Risk Factors in a Rural Tertiary Level Hospital. KYAMC Journal. 2017;8(1).43-8. DOI: https://doi.org/ 10.3329/kyamcj.v8i1.33873

29. Polin RA, Carlo WA. Surfactant replacement therapy for preterm and term neonates with respiratory distress. Pediatrics. 2014;133:156. DOI:10.1542/peds.2013-3443

30. Onyearugha CN, Ugboma HA. Severe birth asphyxia: Risk factors as seen in a tertiary institution in the Niger Delta area of Nigeria. Control J Trop Med. 2010;4:11-19. 